\title{
Does Nutrition Affect Endometriosis?
}

\section{Hat die Ernährung einen Einfluss auf die Endometriose?}

\section{(c) 98}

\author{
Authors \\ Martina Helbig, Anne-Sophie Vesper, Ines Beyer, Tanja Fehm
}

\author{
Affiliation \\ Klinik für Geburtshilfe und Frauenheilkunde, Universitäts- \\ klinikum Düsseldorf, Düsseldorf, Germany
}

Key words

endometriosis, diet, dyspareunia, review

\section{Schlüsselwörter \\ Endometriose, Ernährung, Dyspareunie, Übersicht}

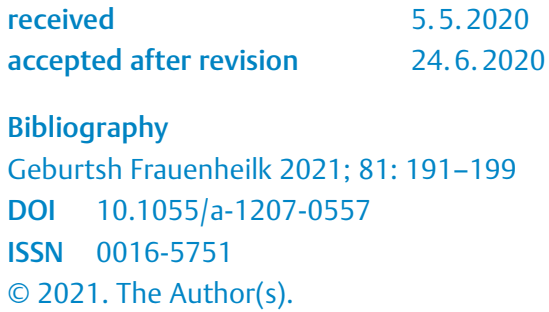
Commons Attribution-NonDerivative-NonCommercial-License, permitting copying and reproduction so long as the original work is given appropriate credit. Contents may not be used for commercial purposes, or adapted, remixed, transformed or built upon. (https://creativecommons.org/licenses/by-nc-nd/4.0/)

Georg Thieme Verlag KG, Rüdigerstraße 14,

70469 Stuttgart, Germany

Correspondence

Dr. Martina Helbig

Universitätsklinikum Düsseldorf, Klinik für Frauenheilkunde und Geburtshilfe

Moorenstraße 5, 40225 Düsseldorf, Germany

martina.helbig@med.uni-duesseldorf.de

Deutsche Version unter:

https://doi.org/10.1055/a-1207-0557

\begin{abstract}
Endometriosis is a hormone-related, chronic inflammation in women of childbearing age. The aetiology and pathogenesis of endometriosis are not yet fully understood. For other illnesses classed as lifestyle diseases, the link between nutrition and pathogenesis has already been researched and proven. With regard to these findings, the question continues to arise as to whether and how a specific diet and lifestyle could also influence pathogenesis and the progression of endometriosis.
\end{abstract}

The aim of this review is to examine the data and determine what influence nutrition has on the development of endometriosis or on existing disease. The study results currently available do not permit a clear, scientific recommendation or indicate a detailed diet. In summary, it can be said that fish oil capsules in combination with vitamin $\mathrm{B}_{12}$ have been associated with a positive effect on endometriosis symptoms (particularly of dysmenorrhoea). Alcohol and increased consumption of red meat and trans fats are associated with a negative effect. The results of the studies listed with regard to fruit and vegetables, dairy products, unsaturated fats, fibre, soy products and coffee are not clear. Therefore, the general recommendations for a balanced and varied diet in line with the guidelines of the Deutsche Gesellschaft für Ernährung e.V. [German Nutrition Society] apply, along with the recommendation to cut out alcohol. In order to be able to derive more concrete recommendations, we require further studies to investigate the influence of nutrition on endometriosis.

\section{ZUSAMMENFASSUNG}

Die Endometriose ist eine hormonabhängige, chronisch entzündliche Erkrankung der Frau im gebärfähigen Alter. Die Ätiologie und Pathogenese der Endometriose sind bis heute nicht abschließend geklärt. Für andere Krankheiten, z. B. sog. „lifestyle diseases“ ist ein Zusammenhang zwischen Ernährung und Pathogenese bereits erforscht und belegt. Hinsichtlich dieser Erkenntnisse taucht immer wieder die Frage auf, ob und wie eine gezielte Ernährung und Lebensweise auch die Krankheitsentstehung und den Verlauf einer Endometriose beeinflussen können. Ziel dieser Übersichtsarbeit ist es, die aktuelle Datenlage zu ordnen und herauszuarbeiten, welchen Einfluss die Ernährung auf die Entstehung der Endometriose bzw. auf eine bereits manifestierte Erkrankung haben könnte. Für eine gezielte, wissenschaftlich fundierte Empfehlung oder einen detaillierten Ernährungsplan reichen die vorliegenden Studienergebnisse bislang nicht aus. Zusammenfassend lässt sich festhalten: Ein positiver Effekt auf die Symptome einer Endometriose (insbesondere der Dysmenorrhö) wird Fischölkapseln in Kombination mit Vitamin $\mathrm{B}_{12}$ zugesprochen. Negativ wirken sich Alkohol sowie die gesteigerte Aufnahme von rotem Fleisch und Transfetten aus. Die Ergebnisse der aufgeführten Studien im Hinblick auf Gemüse und Obst, Milchprodukte, ungesättigte Fettsäuren, Ballaststoffe, Sojaproduk- 
te sowie Kaffee sind nicht eindeutig. Es gelten daher die allgemeinen Empfehlungen zu einer ausgewogenen und abwechslungsreichen Ernährung entsprechend den Regeln der Deutschen Gesellschaft für Ernährung e. V. sowie der Verzicht auf Alkohol. Um konkretere Empfehlungen herleiten zu können, bedarf es weiterer Studien, die den Einfluss der Ernährung auf die Endometriose erforschen.

\section{Introduction}

Endometriosis is a hormone-related, chronic inflammation in women. Approximately 27000 women were treated in hospital for endometriosis in Germany in 2016 [1]. The prevalence is much higher, however, affecting between 5 and $15 \%$ of women of childbearing age [2]. It is characterised by the presence of endometriotic cell clusters outside of the uterine cavity [3]. Typically, they are found in small pockets in the lesser pelvis (endometriosis genitalis interna: recto-uterine pouch, ovaries, Fallopian tubes). External manifestations (endometriosis extragenitalis: scar endometriosis, pulmonary, intestinal) have also been described, but are rare [4]. To date, the aetiology and pathogenesis of endometriosis are not yet fully understood [5,6]. However, immunological, endocrinal, genetic and inflammation factors all appear to play a significant role in its pathogenesis [7-10]. The main symptom is chronic pain in the abdomen and $30-50 \%$ of women experience infertility. This may be accompanied by dysmenorrhoea, dyspareunia, dysuria and dyschezia [11]. The presence of endometriosis may affect and restrict a woman's physical, mental and social well-being [8]. The symptoms are diverse and are often only recognised much later as endometriosis. On average, a woman waits ten years until diagnosis in Germany and Austria [12]. The gold standard is a diagnostic laparoscopy with biopsy in order to confirm endometriosis histologically. Treatment options include surgical removal of the endometriosis lesions and/or drug-based treatment. There are also a range of complementary therapies available [11]. The average treatment costs per woman in ten countries amounted to EUR 9579 per year [13].

\section{Pathogenesis of Endometriosis and Potential Dietary Strategies}

The aetiology and pathogenesis of endometriosis are not yet fully understood. A range of theories as to the pathogenesis of the disease can be found in the literature. One frequently mentioned theory is the transplantation/implantation theory postulated by Sampson in 1921. This theory states that endometriosis is caused by the antegrade and retrograde dispersal of endometrial cells as a result of menstruation. Another hypothesis is the tissue injury and repair hypothesis, according to which autonomic muscle movements cause microtrauma to the endometrium, causing the loose endometrial cells to be carried away. The subsequent repair mechanisms then increase the intrauterine movement, thus creating a vicious circle by which more loose endometrial cells are transported away [14]. In 1919, R. Meyer postulated the metaplasia theory. He believed that the endometrial cells resulted from oestrogen-triggered peritoneal stem cells. Finally, there is also the theory of lymphogenic or haematogenic dispersion of endome- trial cells. At a cellular level, all of these theories result in an inflammation response $[10,15]$. The factors that further facilitate this inflammation require additional, intensive research.

For other illnesses classed as lifestyle diseases (such as coronary heart disease, type 2 diabetes), the link between nutrition and pathogenesis has already been researched and proven. With regard to these findings, the question continues to arise as to whether and how a specific diet and lifestyle could also influence pathogenesis and the progression of endometriosis [7, 16, 17].

The aim of this review is therefore to examine the multifaceted and complex data on the topic of "nutrition and endometriosis" and to determine what influence nutrition has on the development of endometriosis or on existing disease. Two questions in particular are of interest:

1. Can endometriosis be prevented with the right nutrition (preventive approach)?

2. Does diet influence manifest endometriosis or the postoperative condition (therapeutic approach)?

\section{Methods}

A systematic literature review was conducted in PubMed for this report. The review considered articles published since 2000 and listed under the following key words: "endometriosis" in combination with "nutrition", "diet”, "fruits", "vegetables", "fatty acids", “meat”, "alcohol”, "lifestyle”, "caffeine”, "dairy” and "vitamins". The analysis looked at three existing reviews as well as two meta analyses, six case-control studies, two randomised trials and four prospective cohort studies as part of the Nurses' Health Study II ( Table 1).

\section{Review}

\section{Do certain foods or nutrients affect the risk of developing endometriosis?}

The section below deals with the latest study data, investigating whether, and to what extent, various nutrients or dietary components may affect the occurrence of endometriosis (preventive effect). The various components are listed separately below.

\section{Vegetables}

According to one hypothesis, eating lots of vegetables may help to reduce the risk of developing endometriosis. DNA methylation on specific genes involved in the pathogenesis of endometriosis is believed to be responsible [18]. On the other hand, pollutants such as pesticides are suspected of being harmful to health and facilitating the development of endometriosis [19].

Two major case-control studies considered this hypothesis (Parazzini et al. [20], Trabert et al. [21]) postulated divergent re- 
- Table 1 Overview of the studies and articles included in this review.

\begin{tabular}{|c|c|}
\hline Literature & Structure \\
\hline \multicolumn{2}{|l|}{ Case-control studies } \\
\hline \multirow[t]{2}{*}{ Britton et al., 2000} & $\begin{array}{l}\text { Case study group ( } n=673) \text { : Women aged between } 18 \text { and } 74 \text { with confirmed endometrial cysts }(n=280) \\
\text { and women with benign ovarian tumours }(n=393)\end{array}$ \\
\hline & Control group $(n=351)$ : Women without ovarian or endometrial tumours \\
\hline \multirow[t]{2}{*}{ Parazzini et al., 2004} & Case study group ( $n=504)$ : Women aged between 20 and 65 with confirmed endometriosis \\
\hline & Control group ( $n=504)$ : Women aged between 20 and 61 with no gynaecological disorders \\
\hline \multirow[t]{2}{*}{ Heilier et al., 2007} & Case study group ( $n=176)$ : Women with confirmed endometriosis \\
\hline & Control group $(n=88)$ : Women without endometriosis \\
\hline \multirow[t]{2}{*}{ Tsuchiya et al., 2007} & Case study group ( $n=79$ ): Women with confirmed endometriosis \\
\hline & Control group $(n=69)$ : healthy women \\
\hline \multirow[t]{2}{*}{ Trabert et al., 2011} & Case study group ( $n=284$ ): Women aged between 20 and 65 with confirmed endometriosis \\
\hline & Control group $(n=660)$ : healthy women \\
\hline \multirow[t]{2}{*}{ Savaris et al., 2011} & Case study group $(n=25)$ : Women with confirmed endometriosis, grades I-IV \\
\hline & Control group $(n=20)$ : Women with no gynaecological disorders \\
\hline \multirow[t]{2}{*}{ Khanaki et al., 2012} & Case study group $(n=64)$ : Women with confirmed endometriosis \\
\hline & Control group ( $n=74$ ): Women of childbearing age with no gynaecological disorders \\
\hline \multicolumn{2}{|l|}{ Prospective cohort studies } \\
\hline \multicolumn{2}{|c|}{ Evaluation of the Nurses' Health Study II; premenopausal women aged between 25 and 42} \\
\hline \multirow[t]{2}{*}{ Missmer et al., 2010} & 586153 person-years; 1199 cases with endometriosis confirmed by laparoscopy \\
\hline & Control group $(n=69510)$ : healthy women \\
\hline \multirow[t]{2}{*}{ Harris et al., 2013} & 737712 person-years; 1385 cases with endometriosis confirmed by laparoscopy \\
\hline & Control group ( $n=70556)$ : healthy women \\
\hline \multirow[t]{2}{*}{ Harris et al., 2018} & 840012 person-years; 2609 cases with endometriosis confirmed by laparoscopy \\
\hline & Control group $(n=70385)$ : healthy women \\
\hline \multirow[t]{2}{*}{ Yamamoto et al., 2018} & 1019294 person-years; 3800 cases with endometriosis confirmed by laparoscopy \\
\hline & Control group ( $n=81908)$ : healthy women \\
\hline \multicolumn{2}{|l|}{ Cross-sectional study } \\
\hline Hopeman et al., 2015 & 205 people from the database, 25 of whom had histologically confirmed endometriosis \\
\hline \multicolumn{2}{|l|}{ Randomised studies } \\
\hline Deutch et al., 2007 & $\begin{array}{l}78 \text { women aged between } 16 \text { and } 39 \text { with dysmenorrhoea treated for three months either with placebo } \\
(n=18) \text {, seal oil capsules }(n=23) \text {, fish oil capsules }(n=19) \text { or with fish oil capsules and vitamin } B_{12}(n=18)\end{array}$ \\
\hline Sesti et al., 2013 & $\begin{array}{l}222 \text { women with endometriosis grade III-IV who were treated postoperatively with immunosuppressives } \\
(n=69) \text {, dietary supplements }(n=35) \text { or with placebo }(n=110)\end{array}$ \\
\hline \multicolumn{2}{|l|}{ Meta-analyses } \\
\hline Chiaffarino et al., 2014 & 6 case-control studies, 2 cohort studies \\
\hline Parazzini et al., 2013 & 14 case-control studies, 1 cohort study \\
\hline \multicolumn{2}{|l|}{ Reviews } \\
\hline Hansen et al., 2007 & 23 studies, of which $n=12$ "Endometriosis and diet" and $n=11$ "Dysmenorrhoea and diet" \\
\hline Parazzini et al., 2013 & 11 case-control studies, 2 prospective cohort studies \\
\hline Jurkiewicz-Przondziono et al., 2017 & 12 case-control studies, 2 prospective cohort studies \\
\hline
\end{tabular}

sults ( $\triangleright$ Table 2). While Parazzini et al. observed a lower risk (OR $0.3 ; 95 \% \mathrm{Cl} 0.2-0.5$, Ptrend $=0.0001)$, Trabert et al. found no significant differences between women consuming a high amount of green vegetables and women consuming low amounts. Harris et al. [22] were not able to determine any benefits of a vegetable-rich diet in their 2018 prospective survey as part of the Nurses' Health Study II. On the contrary, women consuming $\geq 1$ portion cruciferous vegetables per day had a $13 \%$ higher risk of developing endometriosis $\left(95 \% \mathrm{Cl} 0.95-1.34\right.$; $\left.p_{\text {trend }}=0.03\right)$. The authors explain this with the assumption that the presence or exacerbation of endometriosis-related pain may be linked to gastrointestinal symptoms.

Fruit

Fruit contains antioxidants, which reduce oxygen free radicals thus having the potential to reduce inflammation (reduction in oxidative stress). This may, theoretically, also lower the risk of developing endometriosis [23]. Here, the two case-control studies 
- Table 2 Effects of fruit and vegetable consumption on the occurrence of endometriosis (data from Jurkiewicz-Przondziono et al. [9]).

\begin{tabular}{|c|c|c|}
\hline Literature & Vegetables & Fruit \\
\hline Parazzini et al., 2004 & $\mathrm{P}_{\text {trend }}=0.0001 \mathrm{\nabla}$ & $P_{\text {trend }}=0.002 \Delta$ \\
\hline Trabert et al., 2011 & Not significant & Ptrend $=0.04 \Delta$ \\
\hline Harris et al., 2018 & $\begin{array}{l}\text { Insignificant, or for } \\
\text { cruciferous vegetables } \\
\Delta(\text { Ptrend }=0.03)\end{array}$ & $P_{\text {trend }}=0.004 \mathbf{~}$ \\
\hline
\end{tabular}

from the previous section can once again be used for analysis. While Parazzini et al. [20] demonstrated a lower risk, Trabert et al. [21] described an increased risk with a diet including more fruit ( $\geq 2$ portions fruit a day vs. $\leq 1$ portion a day: OR $1.5,95 \% \mathrm{Cl} 1.2-$ 2.3, Ptrend $=0.04$ ). In their prospective cohort study, however, Harris et al. [22] showed that citrus fruits in particular ( $\geq 1$ portion per day compared to $<1$ portion per week) were able to lower the risk of endometriosis by 22 per cent $(95 \% \mathrm{Cl} 0.69-0.89$; Ptrend $=0.004$ ).

\section{Vitamins}

Antioxidants (such as vitamins $A, C, E$ and $B_{9}$ [folic acid]) reduce the amount of oxygen free radicals and may thus have an anti-inflammatory effect. Three case-control studies have dealt with this hypothesis with regard to the occurrence of endometriosis: Britton et al. 2000 [24], Trabert et al. 2011 [21] and Savaris et al. 2011 [25]. However, none of the three studies was able to significantly prove any link between a vitamin-rich diet (specifically vitamins $A, C$ and $E$ and folic acid) and developing endometriosis.

\section{Fats}

A diet that is high in fat is associated with various health effects, both positive and negative. The different types of fats are considered separately below and the correlation between the study data and occurrence of endometriosis analysed.

\section{Saturated fats}

Saturated fats, which primarily occur in animal-derived products (red meat, ham, butter), are generally associated with few health benefits [26]. Saturated fats may lead to higher plasma concentrations of oestradiol or steroid hormones and are therefore associated with the occurrence of oestrogen-dependent diseases [23]. So, does increased oral consumption of saturated fats correlate with the occurrence of endometriosis?

A total of three case-control studies have addressed the link between eating red meat and/or butter and the risk of developing endometriosis: Parazzini et al. 2004 [20], Heilier et al. 2007 [27] and Trabert et al. 2011 [21] ( $\triangleright$ Table 3). The studies revealed divergent results: While the group under Parazzini showed an increased risk associated with the consumption of red meat (OR $2.0,95 \% \mathrm{Cl} 1.4-2.8$, ptrend $=0.0004$ ), the consumption of butter was not associated with any significant increase in risk in this study [20]. By contrast, Heilier et al. found that the consumption of butter was associated with increased risk (OR 1.87, 95\% Cl 1.003.49) but not the consumption of red meat [27]. Trabert et al. did not find any significant correlation between the occurrence of endometriosis and the consumption of red meat [21].

Three additional studies compared the likelihood of developing endometriosis for women who consumed a diet high in saturated fats and women who ate very low amounts of saturated fats (Britton et al. 2000 [24], Missmer et al. 2010 [7], Savaris et al. 2011 [25]). None of the three studies showed any significant correlation ( Table 3).

In 2018, within the Nurses' Health Study II, Yamamoto et al. [28] were able to show that the consumption of red meat at $>2$ portions/day was associated with a 56 per cent higher risk of developing endometriosis in comparison with women who only ate red meat once a week (95\% Cl 1.22-1.99; $\left.p_{\text {trend }}<0.001\right)$.

\section{Trans fats}

Trans fats, which rarely occur naturally but can be found in processed and deep-fried foods, are generally categorised as being harmful to health [26]. Trans fats are linked with higher levels of inflammation mediators such as TNF-alpha, interleukin 6 and C-reactive protein and, consequently, with increased inflammation $[23,29]$.

- Table 3 Effect of the consumption of saturated fats and a range of foods containing high amounts of saturated fats on the occurrence of endometriosis (data from Parazzini et al. [23]).

\begin{tabular}{|c|c|c|c|c|}
\hline Literature & Saturated fats & Red meat & Ham & Butter \\
\hline Britton et al., 2000 & $\mathrm{p}=0.05 \Delta$ & Not significant & - & - \\
\hline Parazzini et al., 2004 & - & $p=0.0004 \Delta$ & $p=0.001 \Delta$ & Not significant \\
\hline Heilier et al., 2007 & - & Not significant & - & $\mathrm{OR}=1.87 \boldsymbol{\Delta}$ \\
\hline Trabert et al., 2011 & Not significant & Not significant & - & - \\
\hline Missmer et al., 2010 & Not significant & Not significant & - & - \\
\hline Savaris et al., 2011 & Not significant & - & - & - \\
\hline Yamamoto et al., 2018 & - & $\mathrm{P}_{\text {trend }}<0.001 \Delta$ & - & - \\
\hline
\end{tabular}


Two studies have investigated the link between trans fats in the diet and the occurrence of endometriosis. Missmer et al. [7] were able to show that women in the highest quantile for the consumption of trans fats were 48 per cent more likely to develop endometriosis as compared with women whose trans fat consumption was in the lowest quantile $(95 \% \mathrm{Cl} 1.17-1.88$, $\left.P_{\text {trend }}=0.0001\right)$. By contrast, Trabert et al. [21] were not able to determine any significant effect of increased trans fat consumption on the risk of developing endometriosis. The consumption of trans fats via margarine also did not seem to have any effect on the occurrence of endometriosis as shown by the data from Parazzini et al. [20] and Heilier et al. [27] (see also > Table 4).

\section{Monounsaturated fatty acids}

Monounsaturated fatty acids, which occur in olive oil, nuts and milk, for example, have antioxidant properties and have an antiinflammatory effect [30,31]. Six studies considered the effect of the consumption of monounsaturated fatty acids on the risk of developing endometriosis (see $>$ Table 5 ). With regard to the potential effect on the risk of endometriosis, none of the cited studies were able to show any clear correlations.

\section{Polyunsaturated fatty acids}

Polyunsaturated fatty acids (such as omega-3 fatty acids and omega-6 fatty acids) primarily come from fish, seaweed and nuts. They have been proven to play a role in the regulation and reduction of inflammatory prostaglandins and cytokines (interleukins 1 , 2 and 6, TNF-alpha). They were proven to reduce the proliferation of endometriosis lesions both in vivo and in vitro [32,33].

The following clinical trials confirmed this ( $\triangleright$ Table 5 ). Savaris et al. [25] showed that the healthy women in the control group consumed more omega-3 fatty acids than the women with endometriosis ( $p=0.045)$. Within the Nurses' Health Study II, Missmer et al. [7] also determined that developing endometriosis was less likely with a diet rich in omega-3 fatty acids. Women with the highest consumption of omega- 3 fatty acids were 22 per cent less likely to develop endometriosis ( $95 \% \mathrm{Cl} 0.62-0.99$, ptrend $=0.03$ ).

In their cross-sectional study from 2015, Hopeman et al. were also able to show that women with high eicosapentaenoic acid (EPA) levels in their serum had an $82 \%$ lower risk of developing endometriosis than women with lower EPA levels (95\% CI 0.04-0.78; OR 0.18) [34].
- Table 4 Effects of the oral consumption of trans fats or margarine on the occurrence of endometriosis (data from Parazzini et al. [23]).

\begin{tabular}{|l|l|l|}
\hline Literature & Trans fats & Margarine \\
\hline Parazzini et al., 2004 & - & Not significant \\
\hline Heilier et al., 2007 & - & Not significant \\
\hline Missmer et al., 2010 & $\mathrm{p}=0.001 \boldsymbol{\Delta}$ & - \\
\hline Trabert et al., 2011 & Not significant & - \\
\hline $\mathbf{\Delta}=$ increased risk, $\mathbf{v}=$ decreased risk & \\
\hline
\end{tabular}

By contrast, Khanaki et al. [35] were not able to show any correlation between phospholipid levels in the serum (omega-3, omega-6, monounsaturated and polyunsaturated fatty acids) and the occurrence of endometriosis. They concluded that it was not the serum level of phospholipids, but rather the proportion of omega- 3 and omega- 6 fatty acids that influenced the risk of endometriosis.

\section{Dairy products, vitamin D and magnesium}

Vitamin D has been proven to stimulate immunosuppressive regulatory T-cells as well as the secretion of interleukin-10 and inhibits pro-inflammatory interleukin-17 and T-helper cells [36-38].

Kriegel et al. [39] were also able to show that vitamin D deficiency could lead to an increased risk of inflammatory diseases. This could also apply to the occurrence of endometriosis [23].

Harris et al. 2013 [40] were able to show that consumption of low-fat milk and other low-fat dairy products led to a lower risk of disease. Consuming more than three portions of dairy products per day led to an $18 \%$ lower risk as compared with the consumption of two portions (rate ratio $=0.82,95 \% \mathrm{Cl} 0.71-0.95$, $\left.P_{\text {trend }}=0.003\right)$. Furthermore, the study was also able to show an inverse correlation between vitamin $D$ levels and the occurrence of endometriosis. Women with high vitamin D plasma levels had a $24 \%$ lower risk of endometriosis than women with low plasma levels (rate ratio $=0.76,95 \% \mathrm{Cl} 0.60-0.97$; $p_{\text {trend }}=0.004$ ).

However, here, too, there are findings that prove this hypothesis contentious: Parazzini et al. [20] and Heilier et al. [27] were not able to show that milk or cheese had any effect on the occurrence of endometriosis ( $\triangleright$ Table 6 ).

- Table 5 Effect of monounsaturated fatty acids on the risk of developing endometriosis (data from Parazzini et al. [23]).

\begin{tabular}{|c|c|c|c|c|}
\hline Literature & Monounsaturated fatty acids & Polyunsaturated fatty acids & Omega-3 fatty acids & Omega- 6 fatty acids \\
\hline Britton et al., 2000 & $p=0.05 \Delta$ & $\mathrm{p}=0.001 \Delta$ & - & - \\
\hline Parazzini et al., 2004 & - & - & - & - \\
\hline Heilier et al., 2007 & - & - & - & - \\
\hline Trabert et al., 2011 & Not significant & Not significant & Not significant & Not significant \\
\hline Missmer et al., 2010 & Not significant & Not significant & $p=0.03 \nabla$ & Not significant \\
\hline Savaris et al., 2011 & Not significant & - & $p=0.045 \nabla$ & $p=0.006 \nabla$ \\
\hline
\end{tabular}


- Table 6 Effects of vitamin D on the occurrence of endometriosis (data from Jurkiewicz-Przondziono et al. [9]).

\begin{tabular}{|l|l|}
\hline Literature & Vitamin D \\
\hline Parazzini et al., 2004 & Not significant \\
\hline Heilier et al., 2007 & Not significant \\
\hline Trabert et al., 2011 & Not significant (trend $\mathbf{\nabla}$ ) \\
\hline Harris et al., 2013 & $\boldsymbol{\nabla}$ Ptrend $=0.004$ \\
\hline $\mathbf{\Delta}=$ increased risk, $\boldsymbol{\nabla}=$ decreased risk & \\
\hline
\end{tabular}

Several studies have shown that magnesium leads to the relaxation of smooth muscle cells and can thus have an antispasmodic effect $[41,42]$. This suggests that magnesium could influence the pathogenesis of endometriosis (retrograde menstruation) as well as on pain symptoms. Harris et al. [40] were able to demonstrate that the consumption of magnesium was associated with a significantly lower risk of endometriosis $(R R=0.86,95 \% \mathrm{Cl} 0.73-1.01$; Ptrend $=0.007$ ).

Fibre

A high-fibre diet is generally associated with health benefits. In this case, a high-fibre diet means one that is rich in complex carbohydrates with a low glycemic index.

With regard to endometriosis cells, the cell culture study by Nagamani et al. [43] showed that insulin stimulates the proliferation of the endometrium. In particular, refined (low-fibre) carbohydrates with a high glycemic index lead to a rapid spike in insulin levels and insulin-like growth factor 1 . As a result, this hyperinsulinism may reduce levels of the sex hormone binding globulin, leading to hyperoestrogenism [44]. According to the study by Friberg et al., oestrogens and insulin-like growth factor 1 itself promote the proliferation of endometrial cells [45]. These findings therefore indicate increased endometrial proliferation and thus a potentially elevated risk of endometriosis as a result of simple carbohydrates (with a high glycemic index).

In terms of clinical findings, three studies dealt with the link between a high-fibre diet and the occurrence of endometriosis. Trabert et al. [21] and Britton et al. [24] were not able to determine that a high-fibre diet had any significant effect. By contrast, Savaris et al. [25] established that increased fibre intake is associated with an increased risk of developing endometriosis (endometriosis vs. controls, $p=0.023$ ). However, the study population was small, which means that the findings cannot be generalised.

\section{Soya and phytoestrogens (isoflavones)}

As a result of their oestrogenic effects, phytoestrogens, which primarily occur in soya, may be linked with the occurrence of endometriosis and other oestrogen-dependent diseases [46]. One Japanese study [47] was able to determine a correlation between increased isoflavone concentrations in the urine (genistein $\left[p_{\text {trend }}=0.01\right]$ and daidzein $\left[p_{\text {trend }}=0.06\right]$ ) and the occurrence of endometriosis in women with severe disease (grades III-IV). How- ever, this correlation did not apply to patients with milder forms of endometriosis (grades I-II).

Animal models, however, were able to show that the isoflavones genistein and puerarin inhibited aromastase and reduced the expression of oestrogen receptor alpha, which could lead to a reduction in endometriosis lesions due to less oestrogen being available $[48,49]$. Clinical studies have not yet proven this.

\section{Coffee and caffeine}

According to the literature, the consumption of caffeinated beverages increases the availability of oestrogen and oestrones in the follicular phase $[23,50,51]$. Homan et al. [52] were also able to show that caffeine consumption leads to increased concentrations of sex hormone-binding protein (SHBG) and to lower bioavailability of testosterone. This data supports the hypothesis that consumption of coffee and caffeinated beverages may be linked with the occurrence of oestrogen-dependent diseases.

An in-depth meta-analysis by Chiaffarino et al. 2014 [53] was not able to show any evidence of a link between coffee/caffeine consumption and the risk of developing endometriosis (total RR: 1.26, 95\% Cl 0.95-1.66 for caffeine and 1.13 [95\% Cl 0.46-2.76] for coffee consumption).

Alcohol

Alcohol is considered a risk factor for developing oestrogen-dependent diseases [54-56] because it increases the activity of aromatase and thus the availability of oestrogen in the blood [57]. Furthermore, there is a significant correlation between alcohol consumption and the occurrence of some chronic inflammatory diseases [58, 59].

According to a 2013 meta-analysis by Parazzini et al., there is a significant correlation between alcohol consumption and the occurrence of endometriosis [60].

Cassano et al. also described the negative effect of alcohol on the immune system (using psoriasis as an example, also a chronic disease). Regular consumption over a long period in particular influences the immune system as a result of various mechanisms [59]. The authors reported alcohol-related susceptibility to infections as a result of neutropenia, for example, and lower humoral cell response $[61,62]$. At the same time, it triggers pro-inflammatory processes [63-65]. The authors cited the combination of a weakened immune system with an environment facilitating inflammation as the reason for the chronicity of the psoriasis, which could, therefore also be a potential explanation for the probability of chronic endometriosis.

Another aspect worthy of mention here is the effect of alcohol on fertility: Regular consumption has been proven to reduce fertility $[52,54]$. Patients who drink more alcohol as a result of having endometriosis and an unfulfilled wish to have a child thus decrease their fertility even further.

Furthermore, women with confirmed endometriosis have a higher risk of developing depression [66] and thus also a higher risk of alcohol consumption [67].

What remains unclear, however, is whether alcohol consumption can worsen existing endometriosis or affect the severity of the disease [60]. 


\section{Does diet influence endometriosis symptoms or the postoperative condition (therapeutic approach)?}

The following section deals with the potential effect of diet on existing endometriosis (therapeutic effect).

The comprehensive review by Hansen et al. [68] showed that increased consumption of omega-3 fatty acids led to lower pain intensity, lower pain duration and lower painkiller use. Deutch et al. [69] described the consumption of fish oil capsules and vitamin $\mathrm{B}_{12}$ as reducing (by 50 per cent) dysmenorrhoea symptoms. However, it must be borne in mind that the study is already 20 years old and only recorded data using surveys on eating habits.

Sesti et al. investigated the effects of hormone therapy vs. dietrelated measures vs. placebo in a randomised study in women having undergone surgery with more severe endometriosis (rASRM grades III and IV) [70]. The study included 222 women with endometriosis rASRM stages III-IV observed for a total of 12 months post-surgery using a visual analogue scale to assess their pain levels and the SF-36 score to evaluate quality of life. Three post-operative intervention groups were formed: placebo $(n=110)$, hormone replacement $(G n R H$ analogues or estroprogestins) $(n=77)$ and diet (vitamins A, C, E, B 6 , minerals (calcium, magnesium, selenium, zinc, iron), milk starter cultures, fish oil) $(n=35)$. The following symptoms were analysed: dysmenorrhoea, dyspareunia and chronic abdominal pain regardless of menstruation. Women receiving hormone suppressants after surgery or receiving diet-related treatment showed significant pain reductions in all three categories $(p<0.001)$, as well as higher quality of life $(p<0.001)$ as compared with the placebo group.

\section{Discussion and Conclusions}

The question as to whether diet can influence disease is omnipresent. For some diseases, particularly those known as "lifestyle" diseases, there is scientific proof of this (type 2 diabetes, coronary heart disease, etc.). The potential correlation between diet and developing endometriosis is a frequently discussed topic. There are plenty of guides, Internet forums and blogs, radio and TV coverage dealing with the topic and issuing recommendations.

However, from a scientific standpoint, the data is still insufficient and contentious. There are only very few studies that have sufficiently investigated the link between diet and endometriosis. Unfortunately, the results of these few studies are often contradictory ( $\triangleright$ Tables 2 and $\mathbf{3}$ ).

The studies require a closer consideration of their methods and therefore cannot often be directly compared. The study design and number of subjects, for example, vary widely ( $\bullet$ Table 1 ). The comparability of the foods under review requires critical evaluation. The foods compared are also too different and can vary widely in their composition and production methods. For example, milk is mentioned here, but its fat content, processing, origin (organic or conventional farming) has a significant impact on the end product and thus potentially on its dietetic effect. The studies also remain vague in terms of living conditions, other dietary habits, lifestyle and other environmental factors.

Endometriosis is a complex and multifactorial disease, whose pathogenesis is still not yet fully understood. This results in diffi- culties in qualifying or quantifying the effect of diet. There are theories that explain the biological mechanisms and the effect of individual foods, but these theories are often not borne out by epidemiological studies.

The above points indicate the difficulties facing a scientific evaluation of the current data. It was our aim to summarise the current studies investigating "endometriosis and diet" and to analyse them with regard to the effects that diet may have on the pathogenesis and manifestation of endometriosis. Some smaller studies are purposefully mentioned in this review in order to highlight potential minor effects of diet on the occurrence of endometriosis.

The study results currently available do not permit a clear, scientific recommendation or indicate a detailed diet.

With regard to individual foodstuffs, we can say in summary:

- Alcohol consumption [60] and a diet high in trans fats [7] have been shown to have a negative impact on the occurrence of endometriosis.

- The results of the studies listed with regard to fruit and vegetables, dairy products, unsaturated fats, red meat, fibre, soy products and coffee are not clear (see the relevant tables above).

Therefore, the general recommendations for a balanced and varied diet in line with the guidelines of the Deutsche Gesellschaft für Ernährung e.V. [German Nutrition Society] [26] apply, along with the recommendation to cut out alcohol.

In order to be able to derive more concrete recommendations, we require further studies to investigate the influence of nutrition on endometriosis. Attention should be paid to the comparability of the foodstuffs and living conditions.

In addition to epidemiological studies, the authors also recommend conducting experimental research. It would be of particular interest to establish whether and to what extent individual nutrients may affect the different stages of pathogenesis in endometriosis (proliferation, vascularisation, peritoneal invasion, inflammation).

The vague data available so far must be substantiated with studies offering high comparability, and the previous findings from experimental research must be expanded upon. In the bestcase scenario, this may enable the creation of individual nutrition plans and recommendations, which could ease the progression of endometriosis.

\section{Conflict of Interest}

The authors declare that they have no conflict of interest.

\section{References}

[1] Burghaus S, Hildebrandt T, Fahlbusch C et al. Standards Used by a Clinical and Scientific Endometriosis Center for the Diagnosis and Therapy of Patients with Endometriosis. Geburtshilfe Frauenheilkd 2019; 79: 487497

[2] Vinatier D, Orazi G, Cosson M et al. Theories of endometriosis. Eur J Obstet Gynecol Reprod Biol 2001; 96: 21-34

[3] Giudice LC. Endometriosis. N Engl J Med 2010; 362: 2389-2398 
[4] Donnez J, Squifflet J, Casanas-Roux F et al. Typical and subtle atypical presentations of endometriosis. Obstet Gynecol Clin North Am 2003; 30: 83-93

[5] Schweppe K-W. Endometriose: Ist eine Prophylaxe möglich? Gynäkologe 2018; 59: 754-758

[6] Czyzyk A, Podfigurna A, Szeliga A et al. Update on endometriosis pathogenesis. Minerva Ginecol 2017; 69: 447-461

[7] Missmer SA, Chavarro JE, Malspeis $S$ et al. A prospective study of dietary fat consumption and endometriosis risk. Hum Reprod Oxf Engl 2010; 25 : 1528-1535

[8] Bulletti C, Coccia ME, Battistoni $S$ et al. Endometriosis and infertility. J Assist Reprod Genet 2010; 27: 441-447

[9] Jurkiewicz-Przondziono J, Lemm M, Kwiatkowska-Pamuła A et al. Influence of diet on the risk of developing endometriosis. Ginekol Pol 2017; 88: 96-102

[10] Dyson MT, Bulun SE. Cutting SRC-1 down to size in endometriosis. Nat Med 2012; 18: 1016-1018

[11] Ulrich U et al. Leitlinie für die Diagnostik und Therapie der Endometriose. Online: https://www.endometriose-vereinigung.de/files/endometriose/ reiter\%20endometriose/Leitlinie_Diagnostik_Therapie_Endometriose. pdf; last access: 07.11.2019

[12] Hudelist G, Fritzer N, Thomas A et al. Diagnostic delay for endometriosis in Austria and Germany: causes and possible consequences. Hum Reprod Oxf Engl 2012; 27: 3412-3416

[13] Simoens S, Dunselman G, Dirksen C et al. The burden of endometriosis: costs and quality of life of women with endometriosis and treated in referral centres. Hum Reprod Oxf Engl 2012; 27: 1292-1299

[14] Leyendecker G, Wildt L, Mall G. The pathophysiology of endometriosis and adenomyosis: tissue injury and repair. Arch Gynecol Obstet 2009; 280: $529-538$

[15] Taniguchi F. New knowledge and insights about the malignant transformation of endometriosis. J Obstet Gynaecol Res 2017; 43: 1093-1100. doi:10.1111/jog. 13372

[16] Darling AM, Chavarro JE, Malspeis S et al. A prospective cohort study of Vitamins B, C, E, and multivitamin intake and endometriosis. J Endometr 2013; 5: 17-26

[17] Kaiser B, Korell M. Endometriose und Ernährung. Müller \& Steinicke KG Verlag; 2017. ISBN: 9783875691849

[18] McCabe DC, Caudill MA. DNA methylation, genomic silencing, and links to nutrition and cancer. Nutr Rev 2005; 63: 183-195

[19] Kunisue T, Chen Z, Buck Louis GM et al. Urinary concentrations of benzophenone-type UV filters in U.S. women and their association with endometriosis. Environ Sci Technol 2012; 46: 4624-4632

[20] Parazzini F, Chiaffarino F, Surace M et al. Selected food intake and risk of endometriosis. Hum Reprod Oxf Engl 2004; 19: 1755-1759

[21] Trabert B, Peters U, De Roos AJ et al. Diet and risk of endometriosis in a population-based case-control study. Br J Nutr 2011; 105: 459-467

[22] Harris HR, Eke AC, Chavarro JE et al. Fruit and vegetable consumption and risk of endometriosis. Hum Reprod Oxf Engl 2018; 33: 715-727

[23] Parazzini F, Viganò P, Candiani M et al. Diet and endometriosis risk: a literature review. Reprod Biomed Online 2013; 26: 323-336

[24] Britton JA, Westhoff C, Howe $G$ et al. Diet and benign ovarian tumors (United States). Cancer Causes Control 2000; 11: 389-401

[25] Savaris AL, do Amaral VF. Nutrient intake, anthropometric data and correlations with the systemic antioxidant capacity of women with pelvic endometriosis. Eur J Obstet Gynecol Reprod Biol 2011; 158: 314-318

[26] Deutsche Gesellschaft für Ernährung e.V. 10 Regeln der DGE. Online: https://www.dge.de/fileadmin/public/doc/fm/10-Regeln-der-DGE.pdf; last access: 07.11.2019

[27] Heilier J-F, Donnez J, Nackers F et al. Environmental and host-associated risk factors in endometriosis and deep endometriotic nodules: a matched case-control study. Environ Res 2007; 103: 121-129
[28] Yamamoto A, Harris HR, Vitonis AF et al. A prospective cohort study of meat and fish consumption and endometriosis risk. Am J Obstet Gynecol 2018; 219: 178.e1-178.e10

[29] Capobianco A, Monno A, Cottone L et al. Proangiogenic Tie2(+) macrophages infiltrate human and murine endometriotic lesions and dictate their growth in a mouse model of the disease. Am J Pathol 2011; 179: 2651-2659

[30] Owen RW, Giacosa A, Hull WE et al. The antioxidant/anticancer potential of phenolic compounds isolated from olive oil. Eur J Cancer Oxf Engl 1990 2000; 36: 1235-1247

[31] Psaltopoulou T, Kosti RI, Haidopoulos D et al. Olive oil intake is inversely related to cancer prevalence: a systematic review and a meta-analysis of 13,800 patients and 23,340 controls in 19 observational studies. Lipids Health Dis 2011; 10: 127

[32] Calder PC. N-3 polyunsaturated fatty acids and inflammation: from molecular biology to the clinic. Lipids 2003; 38: 343-352

[33] Gazvani MR, Smith L, Haggarty P et al. High omega-3:omega-6 fatty acid ratios in culture medium reduce endometrial-cell survival in combined endometrial gland and stromal cell cultures from women with and without endometriosis. Fertil Steril 2001; 76: 717-722

[34] Hopeman MM, Riley JK, Frolova Al et al. Serum Polyunsaturated Fatty Acids and Endometriosis. Reprod Sci 2015; 22: 1083-1087

[35] Khanaki K, Nouri M, Ardekani AM et al. Evaluation of the relationship between endometriosis and omega- 3 and omega- 6 polyunsaturated fatty acids. Iran Biomed J 2012; 16: 38-43

[36] Correale J, Ysrraelit MC, Gaitán MI. Immunomodulatory effects of Vitamin D in multiple sclerosis. Brain J Neurol 2009; 132: 1146-1160

[37] Hewison M. Vitamin $D$ and the immune system: new perspectives on an old theme. Endocrinol Metab Clin North Am 2010; 39: 365-379

[38] Chambers ES, Hawrylowicz CM. The impact of vitamin D on regulatory T cells. Curr Allergy Asthma Rep 2011; 11: 29-36

[39] Kriegel MA, Manson JE, Costenbader KH. Does vitamin D affect risk of developing autoimmune disease?: a systematic review. Semin Arthritis Rheum 2011; 40: 512-531.e8

[40] Harris HR, Chavarro JE, Malspeis S et al. Dairy-food, calcium, magnesium, and vitamin $\mathrm{D}$ intake and endometriosis: a prospective cohort study. Am J Epidemiol 2013; 177: 420-430

[41] Altura BT, Altura BM. Endothelium-dependent relaxation in coronary arteries requires magnesium ions. $\mathrm{Br}$ J Pharmacol 1987; 91: 449-451

[42] D'Angelo EK, Singer HA, Rembold CM. Magnesium relaxes arterial smooth muscle by decreasing intracellular $\mathrm{Ca} 2+$ without changing intracellular Mg2+. J Clin Invest 1992; 89: 1988-1994

[43] Nagamani M, Stuart CA. Specific binding and growth-promoting activity of insulin in endometrial cancer cells in culture. Am J Obstet Gynecol 1998; 179: 6-12

[44] Kazer RR. Insulin resistance, insulin-like growth factor I and breast cancer: A hypothesis. Int J Cancer 1995; 62: 403-406

[45] Friberg E, Wallin A, Wolk A. Sucrose, high-sugar foods, and risk of endometrial cancer-a population-based cohort study. Cancer Epidemiol Biomarkers Prev 2011; 20: 1831-1837

[46] Andres S, Abraham K, Appel KE et al. Risks and benefits of dietary isoflavones for cancer. Crit Rev Toxicol 2011; 41: 463-506

[47] Tsuchiya M, Miura T, Hanaoka T et al. Effect of soy isoflavones on endometriosis: interaction with estrogen receptor 2 gene polymorphism. Epidemiol Camb Mass 2007; 18: 402-408

[48] Yavuz E, Oktem M, Esinler I et al. Genistein causes regression of endometriotic implants in the rat model. Fertil Steril 2007; 88: 1129-1134

[49] Chen Y, Chen C, Shi S et al. Endometriotic implants regress in rat models treated with puerarin by decreasing estradiol level. Reprod Sci Thousand Oaks Calif 2011; 18: 886-891 
[50] Lucero ], Harlow BL, Barbieri RL et al. Early follicular phase hormone levels in relation to patterns of alcohol, tobacco, and coffee use. Fertil Steril 2001; 76: 723-729

[51] Ferrini RL, Barrett-Connor E. Caffeine intake and endogenous sex steroid levels in postmenopausal women. The Rancho Bernardo Study. Am J Epidemiol 1996; 144: 642-644

[52] Homan GF, Davies M, Norman R. The impact of lifestyle factors on reproductive performance in the general population and those undergoing infertility treatment: a review. Hum Reprod Update 2007; 13: 209-223

[53] Chiaffarino F, Bravi F, Cipriani S et al. Coffee and caffeine intake and risk of endometriosis: a meta-analysis. Eur J Nutr 2014; 53: 1573-1579

[54] Seitz HK, Pelucchi C, Bagnardi V et al. Epidemiology and pathophysiology of alcohol and breast cancer: Update 2012. Alcohol Alcohol 2012; 47: 204-212

[55] Singletary KW, Gapstur SM. Alcohol and breast cancer: review of epidemiologic and experimental evidence and potential mechanisms. JAMA 2001; 286: 2143-2151

[56] Secretan B, Straif K, Baan R et al.; WHO International Agency for Research on Cancer Monograph Working Group. A review of human carcinogens-Part E: tobacco, areca nut, alcohol, coal smoke, and salted fish. Lancet Oncol 2009; 10: 1033-1034

[57] Fernandez SV. Estrogen, alcohol consumption, and breast cancer. Alcohol Clin Exp Res 2011; 35: 389-391

[58] Di Giuseppe D, Alfredsson L, Bottai M et al. Long term alcohol intake and risk of rheumatoid arthritis in women: a population based cohort study. BM] 2012; 345: e4230

[59] Cassano N, Vestita M, Apruzzi D et al. Alcohol, psoriasis, liver disease, and anti-psoriasis drugs. Int J Dermatol 2011; 50: 1323-1331
[60] Parazzini F, Cipriani S, Bravi F et al. A metaanalysis on alcohol consumption and risk of endometriosis. Am J Obstet Gynecol 2013; 209: 106.e1106.e10

[61] Liu YK. Effects of alcohol on granulocytes and lymphocytes. Semin Hematol 1980; 17: 130-136

[62] Imperia PS, Chikkappa G, Phillips PG. Mechanism of inhibition of granulopoiesis by ethanol. Proc Soc Exp Biol Med 1984; 175: 219-225

[63] Ockenfels HM, Keim-Maas C, Funk R et al. Ethanol enhances the IFNgamma, TGF-alpha and IL-6 secretion in psoriatic co-cultures. $\mathrm{Br}$ J Dermatol 1996; 135: 746-751

[64] Crews FT, Bechara R, Brown LA et al. Cytokines and alcohol. Alcohol Clin Exp Res 2006; 30: 720-730

[65] Serwin AB, Sokolowska M, Chodynicka B. Tumour necrosis factor alpha (TNF-alpha)-converting enzyme (TACE) and soluble TNF-alpha receptor type 1 in psoriasis patients treated with narrowband ultraviolet B. Photodermatol Photoimmunol Photomed 2007; 23: 130-134

[66] Sepulcri R de P, do Amaral VF. Depressive symptoms, anxiety, and quality of life in women with pelvic endometriosis. Eur J Obstet Gynecol Reprod Biol 2009; 142: 53-56

[67] Davis L, Uezato A, Newell JM et al. Major depression and comorbid substance use disorders. Curr Opin Psychiatry 2008; 21: 14-18

[68] Hansen SO, Knudsen UB. Endometriosis, dysmenorrhoea and diet. Eur J Obstet Gynecol Reprod Biol 2013; 169: 162-171

[69] Deutch B. Menstrual pain in Danish women correlated with low n-3 polyunsaturated fatty acid intake. Eur J Clin Nutr 1995; 49: 508-516

[70] Sesti F, Pietropolli A, Capozzolo T et al. Hormonal suppression treatment or dietary therapy versus placebo in the control of painful symptoms after conservative surgery for endometriosis stage III-IV. A randomized comparative trial. Fertil Steril 2007; 88: 1541-1547 